\title{
What Are the Risk Factors for Revision Surgery After Hip Arthroscopy for Femoroacetabular Impingement at 7-year Followup?
}

\author{
Pascal Cyrill Haefeli MD, Christoph Emanuel Albers MD, Simon Damian Steppacher MD, \\ Moritz Tannast MD, Lorenz Büchler MD
}

Published online: 7 October 2016

(C) The Association of Bone and Joint Surgeons ( 2016

\begin{abstract}
Background In recent years, surgical treatment of symptomatic femoroacetabular impingement (FAI) has been increasingly performed using arthroscopy. Bony pathomorphologies and damage to the labrum as well as cartilage defects can be addressed with comparable results to open surgery with overall less surgery-related complications. Despite the increasing importance of hip arthroscopy, however, reports on midterm clinical and radiographic outcomes and comparison to open surgical hip dislocation are scarce.
\end{abstract}

One of the authors (MT) has received funding from the Swiss National Science Foundation.

All ICMJE Conflict of Interest Forms for authors and Clinical Orthopaedics and Related Research ${ }^{\circledR}$ editors and board members are on file with the publication and can be viewed on request.

Clinical Orthopaedics and Related Research ${ }^{\mathbb{R}}$ neither advocates nor endorses the use of any treatment, drug, or device. Readers are encouraged to always seek additional information, including FDAapproval status, of any drug or device prior to clinical use.

Each author certifies that his institution approved the human protocol for this investigation, that all investigations were conducted in conformity with ethical principles of research, and that informed consent for participation in the study was obtained.

Electronic supplementary material The online version of this article (doi:10.1007/s11999-016-5115-6) contains supplementary material, which is available to authorized users.

P. C. Haefeli, C. E. Albers, S. D. Steppacher, M. Tannast,

L. Büchler

Department of Orthopaedic Surgery and Traumatology, Inselspital, Bern University Hospital, University of Bern, Bern, Switzerland

L. Büchler $(\bowtie)$

Department of Orthopaedic Surgery, Inselspital, Murtenstrasse,

3010 Bern, Switzerland

e-mail: lorenz.buechler@insel.ch
Questions/purposes (1) What are the clinical and radiographic outcomes at a mean 7-year followup; (2) what is the cumulative 7-year survivorship, using the endpoints of THA, progression of osteoarthritis according to Tönnis, or poor clinical outcome with a Merle d'Aubigné score of less than 15 points, of hips with symptomatic FAI treated arthroscopically; and (3) what factors were associated with revision surgery?

Methods Between 2003 and 2008 we performed a total of 62 arthroscopic procedures (60 patients) for FAI. For the same indication, we also performed 571 surgical hip dislocations during that time. Standardized treatment was femoral offset correction, acetabular rim trimming, or both and treatment of labral or chondral defects. An arthroscopic approach was generally used if the pathomorphology was located in the anterosuperior quadrant of the hip and was gradually used for more complex cases. We excluded 10 hips (10 patients) in which the standardized treatment was not achieved and no offset correction or acetabular rim trimming was performed. Of the remaining 52 hips (50 patients), 39 hips underwent isolated femoral offset correction, four hips isolated acetabular rim trimming, and nine hips both procedures. At a mean followup of 7 years (range, 5-11 years), the Merle d'Aubigné clinical score was obtained and plain radiographs were examined (Tönnis grade, heterotopic ossification, lateral center-edge [LCE] angle, acetabular index [AI], extrusion index, alpha angle, and pistol grip deformity). Cumulative survivorship was calculated according to Kaplan-Meier using conversion to THA, progression of osteoarthritis (one or more Tönnis grades), or poor clinical outcome (Merle d'Aubigné score $<15$ points) as endpoints. Cox regression analysis was used to identify univariate factors associated with revision surgery. 
Results At last followup we detected a significant but possibly not clinically relevant increase in Merle d'Aubigné scores from preoperative levels to latest followup (14 \pm 1 versus $16 \pm 2$, mean difference 2 points with a $95 \%$ confidence interval $[95 \% \mathrm{CI}]-3$ to $7, \mathrm{p}<0.001)$. Six hips showed progression of osteoarthritis. Cumulative survivorship (hips free from conversion to THA, progression of osteoarthritis, or poor clinical outcome) of hips treated with hip arthroscopy for FAI at a mean followup of 7 years was $81 \%$ (95\% CI, 68\%-95\%). Two patients (two hips, $4 \%$ ) underwent THA at 7 and 9 years, respectively. An increased preoperative acetabular coverage (LCE angle, $\mathrm{AI}$ ), increased offset in the superior portion of the femoral neck (pistol grip deformity), and a remaining pistol grip deformity postoperatively were associated with revision surgery. Any treatment of the labrum did not influence the outcome. Factors associated with failure could not be identified.

Conclusions In this series of patients with arthroscopic treatment of symptomatic FAI, hip arthroscopy resulted in an intact hip without progression of osteoarthritis and with a Merle d'Aubigné score of $\geq 15$ points in $81 \%$ of patients at 7-year followup. Increased acetabular coverage and femoral pistol grip deformity were risk factors for revision surgery.

Level of Evidence Level IV, therapeutic study.

\section{Introduction}

Femoroacetabular impingement (FAI) is recognized as a cause of hip pain as well as a potential factor in the development of degenerative arthritis of the hip [20, 21]. Surgical hip dislocation (SHD), initially described in the early 1990s [19], allows an unrestricted visualization of the central and peripheral compartment, evaluation of ROM of the hip, and recognition of damage to the cartilage or labrum caused by an abutment of the femoral neck against the acetabular rim [2]. In addition, SHD provides wide access to the hip to treat bony pathomorphologies like cam deformity, acetabular overcoverage, or femoral malrotation as well as lesions of the cartilage and labrum [19]. There are, however, some disadvantages to treating FAI with SHD such as a relatively long rehabilitation as a result of the osteotomy of the greater trochanter, risk of intraarticular adhesions, trochanteric pain attributable to the screws, and a long scar lateral to the hip [41, 42].

Because of these problems, arthroscopic techniques are a potentially attractive alternative, because no osteotomy of the greater trochanter and full dislocation of the hip has to be performed, with fewer complications related to surgery $[15,30]$ and faster rehabilitation [29]. However, hip arthroscopy has inherent limitations, including restricted access to the acetabulum and posterior aspects of the hip, the need to incorporate a difficult technique with a long learning curve, and risk of under- or overcorrection of FAI pathomorphology. Nevertheless, hip arthroscopy for treatment of FAI is increasingly used [11] and has become the primary treatment option in many centers performing hippreserving surgery. With adequate training, arthroscopic osseous correction $[3,6,16]$ as well as treatment of labral and chondral damages [34, 37] in standard FAI affecting the anterior aspect of the joint can now be performed comparably to open surgery [27]. Most reports on clinical or radiographic results after arthroscopic treatment of FAI are however limited by short-term followup [12, 25] and thus the success or failure of these procedures over time is not known.

We therefore asked: (1) What are the clinical and radiographic outcomes at a mean 7-year followup; (2) what is the cumulative 7-year survivorship (hips free from conversion to THA, progression of osteoarthritis as increased by one or more points on Tönnis score, or poor clinical outcome as a Merle d'Aubigné score of $<15$ points) of hips with symptomatic FAI treated arthroscopically; and (3) what are factors associated with revision surgery?

\section{Patients and Methods}

Between 2003 and 2008 we evaluated more than 700 patients for FAI at our institution. Five hundred eight patients (571 hips) with symptomatic FAI were treated with SHD. Depending on the type of impingement, standardized treatment was femoral offset correction, acetabular rim trimming, and treatment of labral or chondral defects. During the same time, the potential for arthroscopic treatment of hip pathologies was evaluated. As a result of technical limitations, initial indications of hip arthroscopy were limited to the treatment of hip infections, adhesiolysis, labrum resection, or pure diagnostic procedures. With gaining experience, the correction of the offset at the femoral head-neck junction was performed followed by acetabular rim trimming and labrum débridement and reattachment. This resulted in a steady increase of arthroscopically performed FAI surgeries at our institution from $10 \%$ in 2003 to $35 \%$ in 2008 . That group of patients represents the basis of the current study. Included were patients who had no previous surgery or trauma of the hip and were aged 16 years and older. This resulted in 60 patients (62 hips). Excluded were 10 patients (10 hips) in whom the treatment was purely symptomatic without offset correction on the femoral head-neck junction or acetabular 
Table 1. Demographic parameters

\begin{tabular}{ll}
\hline Parameters & Value \\
\hline Number of patients (hips) & $50(52)$ \\
Age at index surgery (years) & $35 \pm 12(16-63)$ \\
Female & $46(89 \%)$ \\
Right side & $34(65 \%)$ \\
Height $(\mathrm{cm})$ & $167 \pm 7(147-182)$ \\
Weight $(\mathrm{kg})$ & $67 \pm 15(47-101)$ \\
Body mass index $\left(\mathrm{kg} / \mathrm{m}^{2}\right)$ & $24 \pm 5(18-38)$ \\
Type of femoroacetabular impingement & \\
Cam-type & $25(48 \%)$ \\
Pincer-type & $13(25 \%)$ \\
Mixed-type & $14(27 \%)$ \\
Type of FAI surgery & \\
Offset correction & $39(75 \%)$ \\
Rim trimming & $4(8 \%)$ \\
Offset and rim addressed & $9(17 \%)$ \\
Additional surgical procedures & \\
Labrum refixation & $4(8 \%)$ \\
Labrum excision & $16(31 \%)$ \\
Adhesiolysis & $2(4 \%)$ \\
\hline
\end{tabular}

Continuous variables expressed as mean $\pm \mathrm{SD}$ (range); FAI = femoroacetabular impingement.

rim trimming. Of those, seven patients had isolated labrum excision and three patients had isolated labrum débridement. Of the remaining 52 hips (50 patients, $89 \%$ female), 39 hips underwent head-neck offset correction, four hips acetabular rim trimming, and nine hips both interventions. In four hips the labrum was reattached, and in 16 hips the labrum was excised (Table 1).

The diagnosis of FAI was established based on the patient's history, clinical examination with a positive impingement sign [23], review of conventional AP pelvis and cross-table lateral hip radiographs [31, 46], and radial MR arthrography. Allocation of hips into cam-, pincer-, or mixed-type FAI was based on parameters on plain radiographs. An alpha angle exceeding $50^{\circ}[33]$ and/or a pistol grip deformity [24] was defined as cam-type FAI. A lateral center-edge (LCE [48]) angle of more than $33^{\circ}[45]$ and/or acetabular index (AI [47]) of less than $3^{\circ}$ [45] was defined as pincer-type impingement. Hips with both cam- and pincer-type pathomorphology were defined as mixed-type FAI (Table 1). During the study period, SHD was the gold standard for the treatment of FAI at our institution. Indications for arthroscopic management were based on a thorough evaluation of the radiographs and MR arthrography to define the size and location of the femoral and acetabular pathomorphology to determine if the necessary correction to achieve impingement-free ROM could be performed arthroscopically. As a result of the technical limitations at the time, hip arthroscopy was only performed in hips in which the pathology was located in the anterosuperior quadrant of the hip. Patients with excessive pincer impingement with protrusio of the femoral head, pronounced acetabular retroversion, cam-type FAI with the pathomorphology exceeding the retinacular vessels, or secondary FAI (residual hip dysplasia, Legg-Calvé-Perthes disease) were treated with open surgical procedures. Hips with advanced signs of arthritis (Tönnis [7] Grade II or higher or signs of advanced cartilage lesions in MR arthrography) were treated nonsurgically or with THA, depending on the severity of symptoms.

Hip arthroscopy was performed as previously described [6]. In summary, surgery was performed under general anesthesia on a traction table. Both the lateral and supine positions were used dependent on the operating surgeon. Most commonly, the anterolateral and midanterior portals were used with access to the central compartment first. The operative plan was established before surgery, but adaptions were made depending on intraoperative findings. On completion of the intervention, the foot was removed from the traction device and impingement-free ROM was tested. Postoperatively, the patients were immediately mobilized on a continuous passive motion machine. Full weightbearing of the operated hip was allowed with the use of two crutches for 2 weeks. Once discharged, the patients were instructed to mobilize the hip with the use of a stationary bicycle to prevent intraarticular adhesions.

Mean followup was $7 \pm 1$ years (range, 5-11 years). At last followup, patients were examined in a standardized manner by one orthopaedic resident (not a treating surgeon, $\mathrm{PCH})$. Complete workup consisted of the patient's history (conversion to THA, revision surgery), written questionnaires to determine the Merle d'Aubigné clinical score [13], and full goniometric ROM examination of the hip. For radiographic followup, conventional AP pelvis and cross-table lateral hip radiographs were assessed for signs of osteoarthritis (Tönnis grade), heterotopic ossifications (Brooker grade [5]), LCE angle, AI, extrusion index [26], crossover sign [36], retroversion index [46], alpha angle, and pistol grip deformity [44]. Analysis of the radiographic parameters was performed with the commercially available software Hip2Norm [49].

Two patients (two hips, 4\%) were lost to followup. Sixteen patients (17 hips, 33\%) did not return for examination at our outpatient clinic, but agreed to complete the questionnaires. Of these patients, 12 patients (13 hips) declined clinical and radiographic examination because they felt well concerning their hip, one patient was not able to come to our outpatient clinic as a result of a decreased general condition not related to the hip, and three patients changed their treating orthopaedic surgeon. Except for a small difference in the proportion of patients with mixed- 
Table 2. Pre- and postoperative clinical parameters

\begin{tabular}{llll}
\hline Parameters & Preoperative & Postoperative & $\mathrm{p}$ value \\
\hline THA & 0 & $2(4 \%)$ & 0.157 \\
Revision surgery & - & $9(17 \%)$ & - \\
Merle d'Aubigné score & $14 \pm 1(8-15)^{*}$ & $16 \pm 2(7-18)$ & $<0.001$ \\
18 points (excellent) & 0 & 6 & 0.014 \\
17 points (very good) & 0 & 21 & $<0.001$ \\
16 points (good) & 0 & 6 & 0.014 \\
15 points (good) & 15 & 9 & 0.221 \\
$<14$ points (fair/poor) & 37 & 6 & $<0.001$ \\
\hline
\end{tabular}

Continuous variables expressed as mean \pm SD (range); *the preoperative Merle d'Aubigné scores were retrospectively calculated.

type FAI, there were no demographic, clinical, or radiographic differences between the patients who completed followup and those that did not (Supplemental Tables 1-3 [Supplemental materials are available with the online version of $\left.C O R R^{\circledR}\right]$ ).

Kolmogorov-Smirnov test was used to determine normal distribution. Comparison of normally distributed continuous variables was performed using a paired t-test; for comparison of nonnormally distributed continuous variables, the Wilcoxon rank-sum test (paired) was used. Comparison of binominal data was done by chi-square test. For survivorship analysis, Kaplan-Meier curves were calculated. Endpoints were conversion to THA, progression of osteoarthritis (one or more Tönnis grades), or poor clinical outcome (Merle d'Aubigné score $<15$ points). To identify univariate factors associated with revision surgery, Cox regression analysis with the endpoint of revision surgery was used. All statistical analysis was performed with WinSTAT $^{\circledR}$ (Version 2012.1; Robert K. Fitch, Bad Krozingen, Germany) in Microsoft ${ }^{\circledR}$ Office Professional Plus 2010 (Version 14.0.7128.5000; (C) Microsoft Corporation, Redmond, WA, USA).

\section{Results}

Two patients (two hips, 4\%) underwent THA at 7 and 9 years, respectively. In the remaining patients we detected a significant but possibly not clinically relevant increase in Merle d'Aubigné scores from preoperative levels to latest followup (14 \pm 1 versus $16 \pm 2$, mean difference 2 with 95\% confidence interval $[\mathrm{CI}],-3$ to $7 ; \mathrm{p}<0.001)$. Eightyseven percent of hips (45 of 52) showed good to excellent results (Merle d'Aubigné 15-18 points), whereas six hips (12\%) had fair or poor results (7-13 points Merle d'Aubigné) (Table 2). Two of these patients had generalized chronic pain syndrome and one patient had depression and conversion disorder; two patients (two hips) did not return for followup examination and no detailed reason for their low scores could be identified. Six hips showed progression of osteoarthritis (Tönnis Grade 1 and 2) and six hips developed heterotopic ossifications (Brooker Grade 1 and 2) (Table 3). Nine hips in nine patients (17\%) underwent revision surgery. In two hips the offset was corrected, in one hip the acetabular rim trimmed, and in six hips both the offset and the rim were addressed. In three of these hips (6\%) the labrum was reattached.

Cumulative survivorship free of THA, progression of osteoarthritis (one or more Tönnis grades), or poor clinical outcome (Merle d'Aubigné score of $<15$ points) of hips treated with hip arthroscopy for FAI at the mean followup of 7 years was $81 \%$ (95\% CI, 68\%-95\%) (Fig. 1).

Various univariate factors associated with revision surgery could be identified. Preoperative factors for revision surgery were LCE angle $>33^{\circ}$ (hazard ratio 4.63 [95\% CI, 1.07-19.94], $\mathrm{p}=0.040)$, AI $<3^{\circ}(95.58$ [95\% CI, 8.02$1162.64], \mathrm{p}<0.001)$, and an increased offset in the superior portion of the femoral neck (pistol grip deformity (1.55 [95\% CI, 1.34-1.78], $\mathrm{p}<0.001$ ). A postoperative factor associated with revision surgery was a remaining high pistol grip deformity (1.05 [95\% CI, 1.00-1.09], $\mathrm{p}=$ 0.035 ). Interventions on the labrum (débridement or excision) did not positively nor negatively influence outcome. With the numbers available, we did not find body mass index (3.89 [95\% CI, 0.97-15.64], $\mathrm{p}=0.056)$ and extrusion index $(0.85$ [95\% CI, 0.73-1.00] [8], $\mathrm{p}=0.051)$ to be associated with a higher risk of failure (Table 4). No factors associated with failure (THA, progression of osteoarthritis, and Merle d'Aubigné score $<15$ points) could be identified.

\section{Discussion}

The goal of surgical treatment of symptomatic FAI is to correct the anatomic abnormalities leading to symptoms and ideally to prevent the development of secondary osteoarthritis. Initially, SHD was the standard of care with generally promising mid- to long-term results [42]. There are, however, some surgery-related disadvantages such as long rehabilitation, the risk for postoperative intraarticular adhesions, or pain over the greater trochanter resulting from the screws [41, 42]. Arthroscopic treatment potentially overcomes these limitations and has become the treatment of choice for FAI in most centers performing hippreserving surgery. Nevertheless, most studies report on short-term followup with only a limited amount of patients. The aim of this study was to report on the 7-year followup of patients undergoing hip arthroscopy for treatment of symptomatic FAI with trimming of the head-neck junction and/or acetabular rim, including treatment of the labrum. 


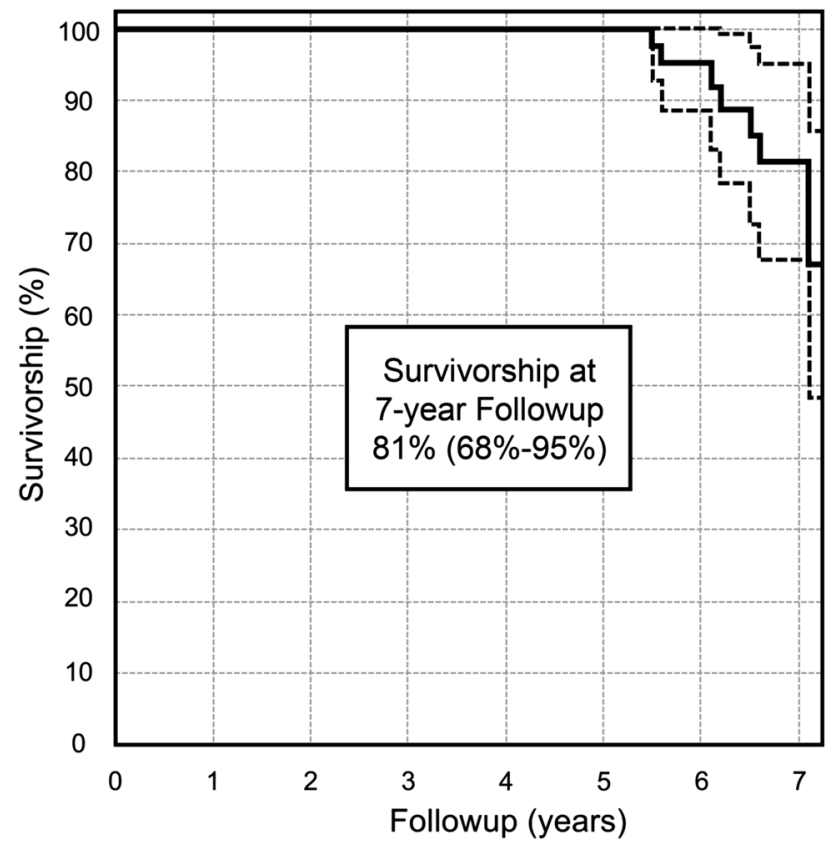

Fig. 1 Survivorship curve according to Kaplan-Meier using conversion to THA, progression of osteoarthritis (Tönnis grade), and poor clinical outcome (Merle d'Aubigné score $<15$ points) as endpoints is shown. The cumulative survival rate was $100 \%$ at 5 years, $95 \%(95 \%$ CI, $89 \%-100 \%)$ at 6 years and $81 \%(95 \%$ CI, $68 \%-95 \%)$ at the 7 -year followup.

We asked the following questions: (1) What is the clinical and radiographic outcome at a mean 7-year followup of arthroscopically treated symptomatic FAI; (2) what is the cumulative 7-year survivorship of arthroscopically treated FAI; and (3) what are factors associated with revision surgery?

This study has several limitations. First, there is a selection toward hips with cam-type impingement. During the study period, SHD was the standard treatment of FAI at our institution. Because we were well aware of the learning curve of hip arthroscopy, the operation was only performed arthroscopically if we felt confident that the necessary interventions to restore normal anatomy of the hip could be achieved. Initially, mainly the osseous bump in cam-type FAI was addressed. This selection of cases helped to avoid insufficient correction but led to the overrepresentation of isolated cam-type FAI in this series (75\%). With advancing experience, also patients requiring acetabular rim trimming, labrum refixation, and cartilage regenerative procedures were increasingly treated using arthroscopy. Nevertheless, only $25 \%$ of all patients included in this study had either isolated or concomitant arthroscopic acetabular rim trimming. We note, therefore, that this is a highly selective group of patients, and results may not translate to a patient with a more complex presentation. Second, clinical scores were not routinely documented preoperatively. From the available data, only the Merle d'Aubigné score can be presented in a comparative way. We detected a statistically detectable increase in the score from preoperative levels to latest followup. However, the mean difference of 2 points may be at or below the level that the typical patient would perceive. The Merle d'Aubigné score was developed to quantify functional results after THA. Although this score is frequently used in literature on hip-preserving surgery, it might not be the most sensitive instrument for these typically young patients. Third, in addition to the two patients (4\%) lost to followup, 16 patients (17 hips, 33\%) did not undergo a full clinical and radiographic followup examination. However, they all completed and returned a detailed questionnaire to obtain clinical scores. None of these 16 patients underwent THA, but four patients had revision surgery. The majority $(88 \%)$ showed good to excellent clinical results in the Merle d'Aubigné score ( $\geq 15$ points). We cannot exclude that the answers given by the patients are as accurate as those obtained with a clinical examination and the study might overstate the benefit of the intervention. In addition, we cannot exclude that patients with good clinical scores had developed asymptomatic arthritis. Patients with a Merle d'Aubigné score of $<15$ points were defined as hips that reached an endpoint. Fourth, we could not identify factors associated with the endpoints conversion to THA, progression of osteoarthritis, or poor clinical outcome (Merle d'Aubigné score $<15$ ). We attribute this to the limited number of 52 hips included in the study and probably too heterogeneous preoperative parameters in the failure cases that led to a lack of statistical power. However, we could identify several univariate factors associated with revision surgery.

At last followup, the mean Merle d'Aubigné score had improved compared with presurgery scores, with $87 \%$ of patients showing good to excellent results. Although statistically detectable, the mean increase from 14 to 16 points might not be clinically significant. Compared with previously reported 5- to 10-year results for a group of patients treated for symptomatic FAI with surgical hip dislocation [42], the patients in the current study had similar Merle d'Aubigné scores, albeit lower preoperative scores. After a better survival rate at 5 years $(100 \%$ for hip arthroscopy versus $91 \%$ for SHD), the cumulative survival rate at 7 year followup using the endpoints conversion to THA, progression of osteoarthritis, or a Merle d'Aubigné score of $<15$ was $81 \%$ (95\% CI, 68-65). The cumulative survival rate found in this study compares well with that after open surgery. At latest followup, 11 hips (21\%) in our study reached an endpoint. Four percent were converted to THA compared with $7 \%$ in the SHD group at 5-year followup, 8\% showed progression of joint degeneration (versus 7\% 5 years after SHD), and 9\% had a Merle 
Table 3. Pre- and postoperative radiographic parameters

\begin{tabular}{|c|c|c|c|c|}
\hline Parameter & Reference values [45] & Preoperative & Postoperative & $\mathrm{p}$ value \\
\hline Lateral center-edge angle (degrees) & $23-33$ & $31 \pm 6(21-46)$ & $29 \pm 5(15-39)$ & $<0.001$ \\
\hline Acetabular index (degrees) & $3-13$ & $3 \pm 6(-8$ to 14$)$ & $5 \pm 6(-5$ to 19$)$ & 0.026 \\
\hline Extrusion index $(\%)$ & $17-26$ & $19 \pm 6(4-36)$ & $20 \pm 6(4-36)$ & 0.107 \\
\hline Crossover sign & Negative & $24(46 \%)$ & $22(42 \%)$ & 0.768 \\
\hline Retroversion index $(\%)$ & 0 & $9 \pm 10(0-39)$ & $7 \pm 10(0-39)$ & 0.115 \\
\hline Alpha angle (degrees) [33] & $<50$ & $59 \pm 11(42-79)$ & $44 \pm 8(32-72)$ & $<0.001$ \\
\hline Pistol grip deformity (degrees) & $<50$ & $43 \pm 8(32-75)$ & $42 \pm 8(32-73)$ & 0.003 \\
\hline \multicolumn{5}{|l|}{ Joint degeneration according to Tönnis } \\
\hline Grade 0 & & $43(83 \%)$ & $17(55 \%)^{*}$ & 0.149 \\
\hline Grade 1 & & $9(17 \%)$ & $13(42 \%)^{*}$ & 0.035 \\
\hline Grade 2 & & 0 & $1(3 \%)^{*}$ & 0.195 \\
\hline \multicolumn{5}{|l|}{ Tönnis progression } \\
\hline Tönnis $0 \rightarrow 1$ & & - & 5 & - \\
\hline Tönnis $1 \rightarrow 2$ & & - & 1 & - \\
\hline \multicolumn{5}{|l|}{ Ossification according to Brooker } \\
\hline Grade 0 & & - & $25(81 \%)^{*}$ & - \\
\hline Grade 1 & & - & $5(16 \%)^{*}$ & - \\
\hline Grade 2 & & - & $1(3 \%)^{*}$ & - \\
\hline
\end{tabular}

Continuous variables expressed as mean \pm SD (range); *percentage of radiographs taken at last followup.

Table 4. Univariate risk factors associated with revision surgery

\begin{tabular}{lcr}
\hline Factor & Hazard ratio & p value \\
\hline Demographic & $5.30(1.08-26.12)$ & 0.040 \\
Left hip & $3.89(0.97-15.64)$ & 0.056 \\
$\mathrm{BMI}>25 \mathrm{~kg} / \mathrm{m}^{2}$ & $0.28(0.07-1.14)$ & 0.075 \\
$\mathrm{BMI}<25 \mathrm{~kg} / \mathrm{m}^{2}$ & \\
Preoperative radiographic parameters & 0.040 \\
LCE angle $>33^{\circ}$ & $4.63(1.07-19.94)$ & 0.045 \\
LCE angle (per $\left.{ }^{\circ}\right)$ & $1.15(1.00-1.32)$ & $<0.001$ \\
AI $<3^{\circ}$ & $95.58(8.02-1162.64)$ & 0.009 \\
AI (per ${ }^{\circ}$ ) & $0.77(0.64-0.94)$ & 0.051 \\
Extrusion index (per \%) & $0.85(0.73-1.00)$ & 0.001 \\
Pistol grip deformity (per $\left.{ }^{\circ}\right)$ & $1.55(1.34-1.78)$ & \\
Surgical interventions $^{2}$ & $3.86(0.40-37.23)$ & 0.242 \\
Labrum refixation $^{\text {Labrum excision }}$ & $0.40(0.08-1.96)$ & 0.260 \\
Postoperative radiographic parameters & \\
Pistol grip (beta angle) & $1.05(1.00-1.09)$ & 0.035 \\
\hline
\end{tabular}

Values expressed as hazard ratio (95\% confidence interval); BMI = body mass index; $\mathrm{LCE}=$ lateral center-edge; $\mathrm{AI}=$ acetabular index.

d'Aubigné score $<15$ points (versus $1 \%$ at 5 years and $3 \%$ at 10 years after SHD) [42]. We did not observe any complications in our patient group. The revision rate of $17 \%$ might partially represent our learning curve and was mainly attributed to insufficient offset correction. Reports on revision rates after hip arthroscopy for FAI are scarce and range from $2 \%$ to $10 \%[8,38]$.

Previous reports on hip arthroscopy for FAI $[9,10,18,22,27,32,35,38]$ show similar results to this study. A direct comparison of failure rates (THA and revision surgery), however, is difficult, because most studies report on a short followup with a variety of clinical scores (Table 5). This is particularly true for conversion to THA, which in this study occurred at 7 and 9 years, respectively. This exceeds the followup time of the available literature. Six hips (12\%) developed heterotopic ossification (Brooker Grade I and II). This is well within the rate reported in the literature [1] and according to Daum et al. [14], these grades are functionally irrelevant. No revision surgery had to be performed because of that reason.

Although we could not find predictors for failure as a result of a lack of statistical power, we could identify several univariate factors that led to revision surgery. Preoperative factors were associated with pincer impingement (high LCE, low AI) or pronounced lateral cam-type impingement (pistol grip deformity), which require a more complex arthroscopic surgical technique for sufficient treatment. Of the 27 hips with pincer- or mixed-type impingement, radiographic parameters could only be normalized in five cases by hip arthroscopy. Residual or unaddressed structural deformity of the hip is a strong predictor for failure after open hip-preserving surgery [40, 42, 43]. Similarly, Bogunovic et al. [4] showed that persisting impingement was the most common 


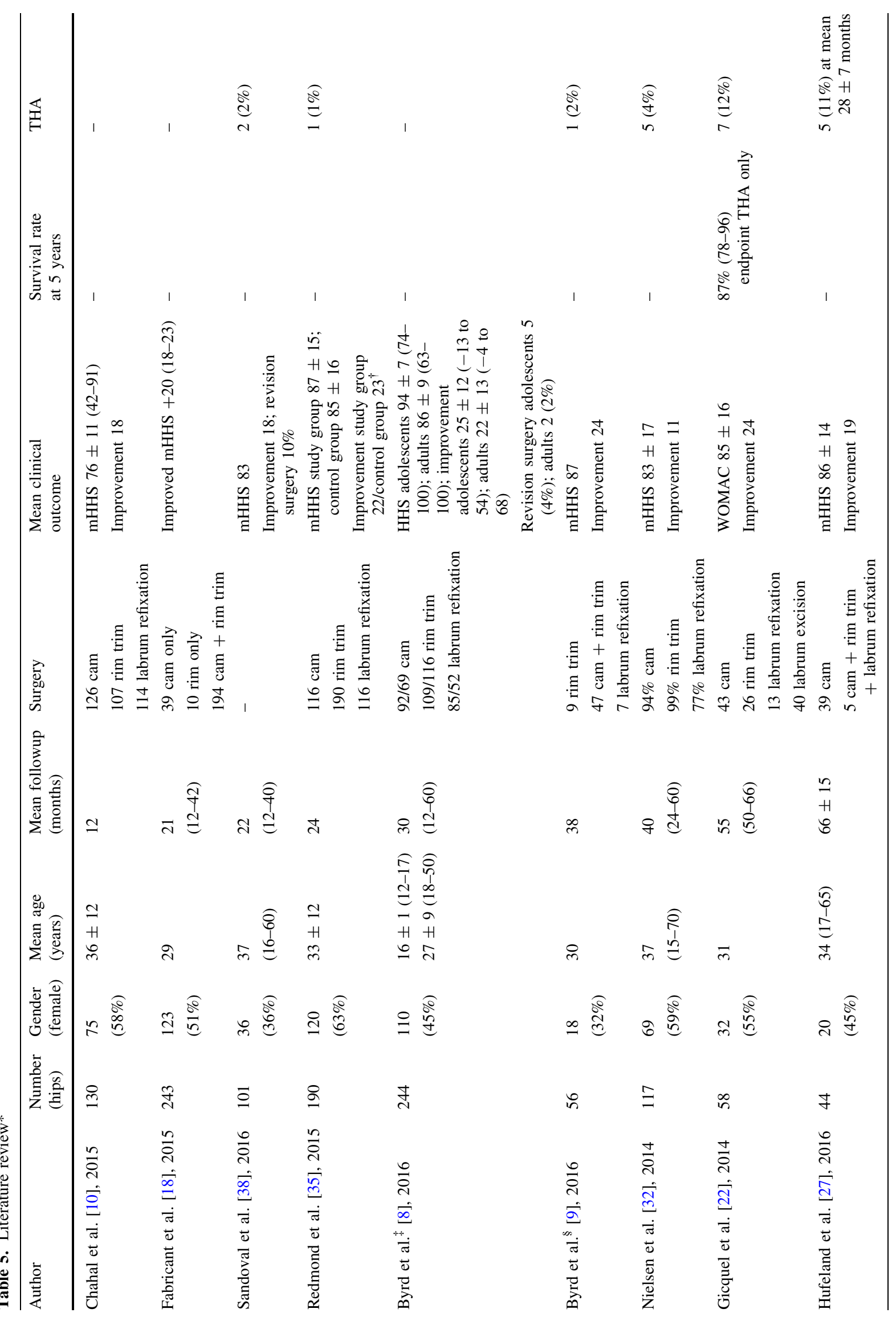




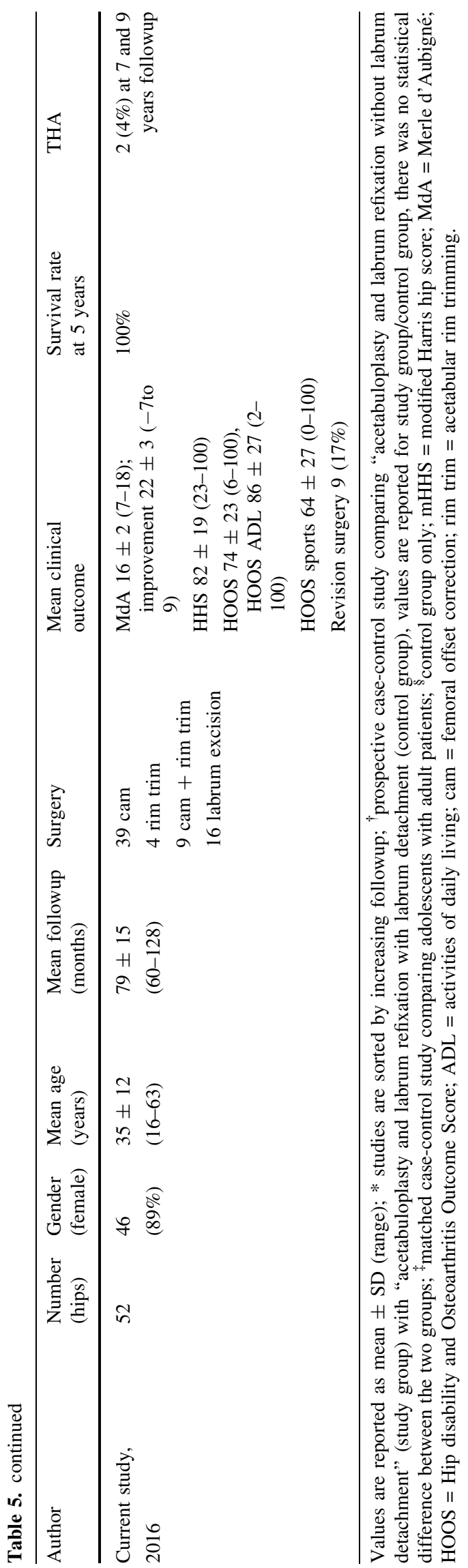

cause of failed hip arthroscopy. Surprisingly, both labrum excision and labrum reattachment had no association with revision surgery. This is in contrast to the reported importance of labral refixation $[17,28,39]$. We attribute this fact to the relatively small number of cases in which we addressed the labrum and the consecutive lack of statistical power.

In summary, hip arthroscopy for treatment of symptomatic FAI resulted in an intact hip without progressive osteoarthritis and with a good or better Mere d'Aubigné score in $81 \%$ of patients at 7 years. Factors associated with revision surgery were pincer-type impingement (increased preoperative LCE and $\mathrm{AI}$ ) and preoperative or remaining postoperative pistol grip deformity. Treatment of the labrum had no influence on revision rate.

\section{References}

1. Amar E, Sharfman ZT, Rath E. Heterotopic ossification after hip arthroscopy. J Hip Preserv Surg. 2015;2:355-363.

2. Beck M, Kalhor M, Leunig M, Ganz R. Hip morphology influences the pattern of damage to the acetabular cartilage: femoroacetabular impingement as a cause of early osteoarthritis of the hip. J Bone Joint Surg Br. 2005;87:1012-1018.

3. Bedi A, Zaltz I, De La Torre K, Kelly BT. Radiographic comparison of surgical hip dislocation and hip arthroscopy for treatment of cam deformity in femoroacetabular impingement. Am J Sports Med. 2011;39(Suppl):20S-28S.

4. Bogunovic L, Gottlieb M, Pashos G, Baca G, Clohisy JC. Why do hip arthroscopy procedures fail? Clin Orthop Relat Res. 2013;471:2523-2529.

5. Brooker AF, Bowerman JW, Robinson RA, Riley LH Jr. Ectopic ossification following total hip replacement. Incidence and a method of classification. J Bone Joint Surg Am. 1973;55:1629-1632.

6. Buchler L, Neumann M, Schwab JM, Iselin L, Tannast M, Beck M. Arthroscopic versus open cam resection in the treatment of femoroacetabular impingement. Arthroscopy. 2013;29:653-660.

7. Busse J, Gasteiger W, Tonnis D. [A new method for roentgenologic evaluation of the hip joint-the hip factor] [in German]. Arch Orthop Unfallchir. 1972;72:1-9.

8. Byrd JW, Jones KS, Gwathmey FW. Arthroscopic management of femoroacetabular impingement in adolescents. Arthroscopy. 2016;32:1800-1806.

9. Byrd JW, Jones KS, Schmitz LM, Doner GP. Hip arthroscopy in the warrior athlete: 2 to 10 year outcomes. J Hip Preserv Surg. 2016;3:68-71.

10. Chahal J, Van Thiel GS, Mather RC 3rd, Lee S, Song SH, Davis AM, Salata M, Nho SJ. The patient acceptable symptomatic state for the modified Harris hip score and Hip Outcome Score among patients undergoing surgical treatment for femoroacetabular impingement. Am J Sports Med. 2015;43:1844-1849.

11. Cvetanovich GL, Chalmers PN, Levy DM, Mather RC 3rd, Harris JD, Bush-Joseph CA, Nho SJ. Hip arthroscopy surgical volume trends and 30-day postoperative complications. Arthroscopy. 2016;32:1286-1292.

12. Cvetanovich GL, Harris JD, Erickson BJ, Bach BR Jr, BushJoseph CA, Nho SJ. Revision hip arthroscopy: a systematic review of diagnoses, operative findings, and outcomes. Arthroscopy. 2015;31:1382-1390.

13. d'Aubigne RM, Postel M. The Classic: Functional results of hip arthroplasty with acrylic prosthesis. 1954. Clin Orthop Relat Res. 2009;467:7-27. 
14. Daum WJ, Scarborough MT, Gordon W Jr, Uchida T. Heterotopic ossification and other perioperative complications of acetabular fractures. J Orthop Trauma. 1992;6:427-432.

15. de Sa D, Stephens K, Parmar D, Simunovic N, Philippon MJ, Karlsson J, Ayeni OR. A comparison of supine and lateral decubitus positions for hip arthroscopy: a systematic review of outcomes and complications. Arthroscopy. 2016;32:716-725 e718.

16. Domb BG, Stake CE, Botser IB, Jackson TJ. Surgical dislocation of the hip versus arthroscopic treatment of femoroacetabular impingement: a prospective matched-pair study with average 2year follow-up. Arthroscopy. 2013;29:1506-1513.

17. Espinosa N, Rothenfluh DA, Beck M, Ganz R, Leunig M. Treatment of femoro-acetabular impingement: preliminary results of labral refixation. J Bone Joint Surg Am. 2006;88:925-935.

18. Fabricant PD, Fields KG, Taylor SA, Magennis E, Bedi A, Kelly BT. The effect of femoral and acetabular version on clinical outcomes after arthroscopic femoroacetabular impingement surgery. J Bone Joint Surg Am. 2015;97:537-543.

19. Ganz R, Gill TJ, Gautier E, Ganz K, Krugel N, Berlemann U. Surgical dislocation of the adult hip a technique with full access to the femoral head and acetabulum without the risk of avascular necrosis. J Bone Joint Surg Br. 2001;83:1119-1124.

20. Ganz R, Leunig M, Leunig-Ganz K, Harris WH. The etiology of osteoarthritis of the hip-an integrated mechanical concept. Clin Orthop Relat Res. 2008;466:246-272.

21. Ganz R, Parvizi J, Beck M, Leunig M, Nötzli H, Siebenrock KA. Femoroacetabular Impingement-a cause for osteoarthritis of the hip. Clin Orthop Relat Res. 2003;417:112-120.

22. Gicquel T, Gedouin JE, Krantz N, May O, Gicquel P, Bonin N, SoFcot. Function and osteoarthritis progression after arthroscopic treatment of femoro-acetabular impingement: a prospective study after a mean follow-up of $4.6(4.2-5.5)$ years. Orthop Traumatol Surg Res. 2014;100:651-656.

23. Hananouchi T, Yasui Y, Yamamoto K, Toritsuka Y, Ohzono K. Anterior impingement test for labral lesions has high positive predictive value. Clin Orthop Relat Res. 2012;470:3524-3529.

24. Harris WH. Traumatic arthritis of the hip after dislocation and acetabular fractures: treatment by mold arthroplasty. An end-result study using a new method of result evaluation. J Bone Joint Surg Am. 1969;51:737-755.

25. Hetaimish BM, Khan M, Crouch S, Simunovic N, Bedi A, Mohtadi N, Bhandari M, Ayeni OR. Consistency of reported outcomes after arthroscopic management of femoroacetabular impingement. Arthroscopy. 2013;29:780-787.

26. Heyman $\mathrm{CH}$, Herndon $\mathrm{CH}$. Legg-Perthes disease; a method for the measurement of the roentgenographic result. $J$ Bone Joint Surg Am. 1950;32:767-778.

27. Hufeland M, Kruger D, Haas NP, Perka C, Schroder JH. Arthroscopic treatment of femoroacetabular impingement shows persistent clinical improvement in the mid-term. Arch Orthop Trauma Surg. 2016;136:687-691.

28. Larson CM, Giveans MR, Stone RM. Arthroscopic débridement versus refixation of the acetabular labrum associated with femoroacetabular impingement: mean 3.5-year follow-up. Am J Sports Med. 2012;40:1015-1021.

29. Lee JB, Kang C, Lee CH, Kim PS, Hwang DS. Arthroscopic treatment of synovial chondromatosis of the hip. Am J Sports Med. 2012;40:1412-1418.

30. Matsuda DK, Philippon MJ, Safran MR, Sampson TG. Hip arthroscopy: tales from the crypt. Instr Course Lect. 2016;65:437-445.

31. Meyer DC, Beck M, Ellis T, Ganz R, Leunig M. Comparison of six radiographic projections to assess femoral head/neck asphericity. Clin Orthop Relat Res. 2006;445:181-185.
32. Nielsen TG, Miller LL, Lund B, Christiansen SE, Lind M. Outcome of arthroscopic treatment for symptomatic femoroacetabular impingement. BMC Musculoskelet Disord. 2014;15:394.

33. Notzli HP, Wyss TF, Stoecklin CH, Schmid MR, Treiber K, Hodler J. The contour of the femoral head-neck junction as a predictor for the risk of anterior impingement. J Bone Joint Surg Br. 2002;84:556-560.

34. Philippon MJ, Arnoczky SP, Torrie A. Arthroscopic repair of the acetabular labrum: a histologic assessment of healing in an ovine model. Arthroscopy. 2007;23:376-380.

35. Redmond JM, El Bitar YF, Gupta A, Stake CE, Vemula SP, Domb BG. Arthroscopic acetabuloplasty and labral refixation without labral detachment. Am J Sports Med. 2015;43:105-112.

36. Reynolds D, Lucas J, Klaue K. Retroversion of the acetabulum. A cause of hip pain. J Bone Joint Surg Br. 1999;81:281-288.

37. Sampson TG. Arthroscopic treatment for chondral lesions of the hip. Clin Sports Med. 2011;30:331-348.

38. Sandoval E, Martin-Rios MD, Cimas D, Masegosa A, Calvo E. Hip arthroscopy for the treatment of femoroacetabular impingement: a comparative study between the classic and the outside-in access. Hip Int. 2016;26:290-294.

39. Schilders E, Dimitrakopoulou A, Bismil Q, Marchant P, Cooke C. Arthroscopic treatment of labral tears in femoroacetabular impingement: a comparative study of refixation and resection with a minimum two-year follow-up. J Bone Joint Surg Br. 2011;93:1027-1032.

40. Siebenrock KA, Schaller C, Tannast M, Keel M, Buchler L. Anteverting periacetabular osteotomy for symptomatic acetabular retroversion: results at ten years. J Bone Joint Surg Am. 2014;96:1785-1792.

41. Sink EL, Beaule PE, Sucato D, Kim YJ, Millis MB, Dayton M, Trousdale RT, Sierra RJ, Zaltz I, Schoenecker P, Monreal A, Clohisy J. Multicenter study of complications following surgical dislocation of the hip. J Bone Joint Surg Am. 2011;93:1132-1136.

42. Steppacher SD, Anwander H, Zurmuhle CA, Tannast M, Siebenrock KA. Eighty percent of patients with surgical hip dislocation for femoroacetabular impingement have a good clinical result without osteoarthritis progression at 10 years. Clin Orthop Relat Res. 2015;473:1333-1341.

43. Steppacher SD, Tannast M, Ganz R, Siebenrock KA. Mean 20year followup of Bernese periacetabular osteotomy. Clin Orthop Relat Res. 2008;466:1633-1644.

44. Stulberg S, Cordell L, Harris W, Ramsey P, MacEwen G. Unrecognized childhood hip disease: a major cause of idiopathic osteoarthrits of the hip. In: The Hip Society, ed. The Hip: Preceedings of the Third Open Scientifc Meeting of the Hip Society. St Louis, MO, USA: CV Mosby; 1975.

45. Tannast M, Hanke MS, Zheng G, Steppacher SD, Siebenrock KA. What are the radiographic reference values for acetabular under- and overcoverage? Clin Orthop Relat Res. 2015;473:1234-1246.

46. Tannast M, Siebenrock KA, Anderson SE. Femoroacetabular impingement: radiographic diagnosis-what the radiologist should know. AJR Am J Roentgenol. 2007;188:1540-1552.

47. Tönnis D. General radiography of the hip joint. In: Tönnis D, ed. Congenital Dysplasia, Dislocation of the Hip. New York, NY, USA: Springer; 1987:100-142.

48. Wiberg G. Studies on dysplastic acetabula and congenital subluxation of the hip joint: with special reference to the complication of osteoarthritis. Acta Chir Scand. 1939;83:1135.

49. Zheng G, Tannast M, Anderegg C, Siebenrock KA, Langlotz F. Hip2Norm: an object-oriented cross-platform program for 3D analysis of hip joint morphology using 2D pelvic radiographs. Comput Methods Programs Biomed. 2007;87:36-45. 